\title{
Reducing recurrent care proceedings: initial evidence from new interventions
}

\author{
Pamela Cox ${ }^{\mathrm{a}}$, Caroline Barratt ${ }^{\mathrm{b}}$, Frances Blumenfeld ${ }^{\mathrm{b}}$, Zara Rahemtulla ${ }^{\mathrm{b}}$, \\ Danny Taggart ${ }^{\mathrm{b}}$ and Jackie Turton ${ }^{\mathrm{a}}$
}

${ }^{a}$ Department of Sociology, University of Essex, Colchester, UK; ${ }^{b}$ School of Health and Human Sciences, University of Essex, Colchester, UK

\begin{abstract}
The English family justice system faces a crisis of recurrence. As many as one in four birth mothers involved in public law care proceedings in English family courts are likely to reappear in a subsequent set of proceedings within seven years. These mothers are involved in up to one-third of total care applications, as they are - by definition - linked to more than one child . Few birth mothers experiencing the removal of a child to care are offered any follow-up support, despite often facing multiple challenges including poverty, addiction, domestic violence and mental health problems. Since 2011, however, a number of new services have been established to begin to address their unmet needs. This article summarises the findings of the first academic-led evaluation of two of these initiatives. Presenting evidence from a mixed-methods evaluative study, it concludes that the new services were able to foster relationships that 'worked' in reducing recurrent proceedings. None of the women engaging with the services went on to experience what could be described as a 'rapid repeat pregnancy' within the evaluation window. Just as significantly, a number of clients reported some improvement in their psychological functioning, and the practitioners involved reported positively on their experience of delivering and managing innovative services. The article closes with a discussion of the challenges of evaluating personalised, strengths based interventions and the possibilities of evidencing empowerment in these cases.
\end{abstract}

\section{Keywords}

Recurrent care proceedings; child protection; birth mothers; evaluation 


\section{Recurrent care proceedings: a national challenge}

The state's power to remove a child from his or her birth parent is one of its most far-reaching. That power is exercised more frequently in England and Wales than in many other countries around the world, particularly in respect of the removal of infants and younger children (Borzova, 2015; Gilbert, Parton, \& Skivenes, 2011). In recent years, there has been a marked upward trend in care applications - up from 5.9 per 10,000 children in 2008-2009 to 9.6 in 2012 to 2013 (Cafcass, 2014) and a pronounced rise in the number of those applications involving young babies - up from 802 in 2008 to 2018 in 2013 (Broadhurst, Alrouh, et al., 2015; cited by BBC News, 2015). Most cases are initiated by local authority safeguarding teams on the grounds that a child faces the risk of significant harm. Harm here is defined by the Children Act 1989 (section 31) as ill-treatment or impairment of health and development. Care applications made under the Act can have one of the four outcomes if a family court deems intervention necessary: adoption, out-of-home care, family and friends care or home supervision. ${ }^{1}$

The recent upward trend in English care applications divides opinion. For some commentators, it is evidence of a child protection system that prioritises a child's right to safety over a parent's right to retain the care of that child (see, for example, Dale, Green, \& Fellows, 2005; Ward, Brown, \& Westlake, 2012). For others, it is evidence of a system dominated by risk assessment mechanisms that ignore, or fail to build on, signs of safety within a family (see, for example, De Bortoli \& Dolan, 2014; Wilkins, 2013). What has received very little attention within these debates, however, is the part played by recurrent cases in shaping these family court trends

Pioneering research has now established a new national data-set revealing, for the first time, the incidence of recurrent care proceedings. Broadhurst, Alrouh, et al. (2015) have used national records gathered by the Child and Family Court Advisory and Support Service (Cafcass) to identify 43,541 birth mothers involved in proceedings under section 31 of the 1989 Children Act in English family courts over a seven-year window (2007-2014). Their analysis shows that one in every four mothers $(23.7 \%)$ involved in an initial case is likely to reappear in a subsequent set of proceedings within seven years. These mothers are involved in up to one-third of total care applications as they are - by definition - linked to more than one child. Recurrence is most likely to occur within two years of initial proceedings: over half (13.2\%) of the total recurrent cases occur within the first two years of an initial case and is more pronounced among the younger mothers in the sample.

Research on the experiences of birth mothers involved in these cases in the UK remains relatively rare. Howe et al.'s classic study (1992), Half a Million Women, includes interviews with some of the many women who had given up children for adoption (through voluntary as well as statutory processes) and raised important questions about their experiences of broken attachment and loss. These feelings were powerfully evoked in Still Screaming (Charlton, Crank, Kansara, \& Oliver, 1998), a study that revealed the ongoing pain and deep grief experienced by many women in this situation. More recently, Cossar and Neil (2010) have further explored the very difficult emotions bound up with losing children to permanent adoption and the support organisations, such as the Family Rights Group, which give voice to birth parents and offer advocacy services (Lindley \& Richards, 2002).

Further, there is strong recent research evidence to suggest that women who have had children removed from their care suffer a marked downturn in psychological functioning (After Adoption, 2007; Logan, 1996; Neil, Cossar, Lorgelly, \& Young, 2010). Most recently, Broadhurst and Mason (2013) found qualitative evidence for this decline, and larger US studies have echoed this observation (Grant, Graham, Ernst, Peavy, \& Brown, 2014; Ryan, Choi, Hong, Hernandez, \& Larrison, 2008). It should be noted that research in this area has, up to now, focused on cases of relinquishment rather than removal.

\section{Reducing recurrent care proceedings: new local initiatives}

Until recently, few birth mothers have been offered any support in the weeks and months following the removal of their child(ren), despite often facing multiple interrelated challenges including social exclusion, material disadvantage, addiction, domestic violence and mental health problems. Since 2011 , however, a number of new discrete services have been established by local authorities and voluntary agencies to begin to address the unmet needs of this group. Among the first were initiatives developed in Suffolk (the subject of the evaluation summarised here) as well as in Brighton, Reading, 
Salford, Nottingham and Hackney. The initial Hackney service, named Pause, has since received significant media coverage (BBC Radio Four Woman's Hour's, 2014; Hill, 2014) and funding from the Department for Education to test its approach in six English locations: Doncaster, Greenwich, Hull, Islington, Newham and Southwark (Pause, 2015a). To date, no formal evaluation of these initiatives has been published.

This article begins to address the fact that as, Broadhurst, Alrouh, et al. (2015, p. 2241) observe, there remains a 'dearth of research to inform a prevention agenda'. It summarises the findings of the first academic-led evaluation of two new services working in partnership to reduce recurrent care proceedings (Cox et al., 2015). ${ }^{2}$ The first service, Positive Choices, launched in September 2013 and is run by Suffolk County Council's safeguarding team. It emerged from earlier pilots developed in 2010 at the margins of existing services through the work of the South Suffolk Pre-Birth Working Group, an informal affiliation of frontline women practitioners across social work, midwifery and safeguarding and motivated by a shared determination to tackle recurrence at the ground-level (Cox, 2012; South Suffolk Pre- Birth Working Group, 2011). The second, M Power, is run by Ormiston Families, a voluntary agency specialising in supporting families in challenging circumstances. It was informed by these earlier pilots but also by Ormiston's own organisational history of developing innovative relationship-based work with marginal groups. The two services are operated by very small teams, supported by a larger group of stakeholders from both partner and related organisations. Positive Choices employs one part-time manager and two full-time support workers and M Power one part-time manager and one support worker. All have extensive experience of working with marginal and vulnerable adults.

Positive Choices and M Power offer intensive support to women in Suffolk who have had at least one child removed from their care by a local authority. Some retain formal contact with their child(ren), notably in cases where an extended family member has become their main carer. In some cases, service support is extended to their partners, if all parties are willing. Women are typically referred via safeguarding managers within children's social care services, safeguarding midwives and mental health services. All referrals are initially assessed by Positive Choices' staff to determine their likely levels of engagement and capacity for change. Those who are believed to meet service entry thresholds are then allocated a support worker in one of the two services.

Neither service is tied to a fixed intervention model or to a particular theory of change. Rather, they offer a pragmatic, client-led approach, based on one-to-one support, self-care and trust-building. Once a relationship has been established between a woman and her support worker, personal goals - often very modest at first - are identified along with practical ways of achieving these. The support offered is therefore flexible and individually tailored, with some women opting for quite intensive contact and others less so. Support workers maintain contact with the women through face-to-face visits, phone calls, texts and emails as well as through personal letters and cards. They also assist and encourage the women to engage with other community-based services as well as supporting them to access longterm contraception. Neither service currently sets a fixed time limit for support offered.

Positive Choices and M Power can be described as offering a strengths-based intervention in that they seek to identify particular personal capacities that could form personal foundations for change. In common with other strengths-based initiatives, they acknowledge personal deficits and risks but seek to challenge clients to find ways of countering their harmful effects. This approach connects with a broader movement within child protection influenced by the 'signs of safety' model first developed in the 1990s in Australia and now widely adopted by local authority safeguarding teams in England which, similarly, seeks to identify and cultivate future parental competence (Bunn, 2013; Turnell \& Edwards, 1999). It also connects with initiatives within the criminal and youth justice field, notably around programmes, such as AssetPlus, that support individual pathways to desistance (Disley, Rubin, Scraggs, Burrowes, \& Culley, 2011; Youth Justice Board, 2014); and within the health psychology field, particularly around new theories of behaviour change (Michie \& Johnston, 2012). New strengths-based approaches like these - often highly flexible, often with outcome goals shaped by practitioner discretion and client preference, often seeking to evidence client 'empowerment' require new kinds of evaluation strategies

In shaping our own mixed method research design, we were mindful of these issues and the challenges they generate. We were also sympathetic, to a degree, with Featherstone, White, and 
Morris' (2014, p. 9) recent critique of the 'evidence-based paradigm' dominating assessments of 'manualised parenting programmes' within child protection that 'reinforce abstraction' to a point that apparently 'removes the need for conversations [our emphasis] with parents about what their lives are like, and what hopes and fears they have for themselves, their children and their relationships'.

However, we would argue that generating robust evidence about the impacts of new initiatives - like Positive Choices and M Power - is vital in shaping the further development (and likely commissioning) of creative and co-produced practice.

\section{Mixed methods empowerment evaluation strategies}

As interventions become increasingly personalised, mixed methods evaluations are becoming increasingly important within evidence-based policy-making. In framing our methodology, we were mindful of the 'hierarchies of evidence' (Featherstone et al., 2014, p. 15) used by service commissioners to establish 'what works' and, by extension, to determine 'what should be funded'. The views and voices of service users and practitioners, gathered through new kinds of qualitative approaches, are rapidly advancing up these hierarchies. At the same time, a more creative range of quantitative measures is being used to pinpoint micro-level changes in wellbeing and personal functioning as well as macro-level changes in the socio-economic position of given populations. In an effort to 'hit' all these 'targets', we have combined insights from realist, mixed method and empowerment evaluation models.

We share the view of realist evaluators that it is not interventions themselves which 'work' but the reasoning and opportunities of the people delivering and experiencing the programmes which makes them work (Pawson \& Tilley, 1994, 1997). This view, plus our own experiences as an interdisciplinary team spanning sociology, health and clinical psychology as well as a range of practitioner roles, shaped our commitment to developing a mixed methods evaluation model that combines qualitative and quantitative approaches. ${ }^{3}$ Here, we have sought to apply key mixed method principles as summarised by Burch and Heinrich (2016), notably the principle that the selected methods should be integrated across the 'entire cycle of the research process', through planning, data collection, analysis, dissemination and redesign and that their use should be interactive and iterative across the process. Finally, we have adapted elements of empowerment evaluation (Fetterman, 1994; Fetterman, Kaftarian, \& Wandersman, 2015), initially developed in the 1990s as a means of empowering organisations and client communities by delivering interventions through collaborative working and collective ownership of goals. We have extended this notion to explore the possibilities of evidencing 'empowerment' at the individual client level. We have sought to operationalise this by seeking sensitive ways of describing and measuring the personal and psychological impacts of strengths-based interventions. We discuss elsewhere the many challenges of defining, measuring and theorising 'empowerment' in this context (Cox \& Turton, 2016).

From the outset, our evaluation methodology was developed in dialogue with the two Suffolk services. Members of the team met with practitioners at the research design process stage to better understand their organisational aims and challenges, and their own groundlevel theories of change - in other words, their shared view of the kinds of changes likely to improve clients' quality of life and their future ability to parent effectively, if they chose to do so. Outcome measures were agreed as part of this process. 'Hard' outcomes included: the number of avoided pregnancies likely to result in the removal of a baby and associated avoided financial costs; the number of onward referrals of women to other community-based services; women's access to education, training and work. 'Soft' outcomes included changes in clients' self-esteem, in their ability to make decisions and set personal goals, in the quality of their attachment relationships, and their mental health symptomatology.

Significantly, the services do not actively seek to assist participants to be able to better manage any future pregnancies. Rather, they seek to develop more generic coping and self-actualisation skills. They are very mindful that they cannot offer any 'guarantee' that participants will not face family court proceedings in relation to any future children they may have. However, practitioners agreed that if participants were able to demonstrate progress around these 'soft' outcome indicators, this was likely to enhance their capacity to cope with the demands of a further pregnancy. 


\section{Data collection and sampling}

\section{Baseline data}

Baseline data were collected on 82 clients ( 74 women and 8 men) and covered the duration, nature and broad outcomes of their engagement with the two services. ${ }^{4}$ This data were based on practitioners' assessments of individual client experience and progress. It was gathered by the evaluation team as an interim measure pending the finalisation by the two services of a more comprehensive system for capturing client progress against revised goals as the interventions develop. It should be noted that, due to operational constraints, it was not always possible for practitioners to offer a full assessment for all clients across all indicators.

\section{Self-report clinical measures}

Clinical data were collected on 12 clients (nine women and three men). In line with the soft outcomes agreed with practitioners (outlined above), we selected six self-report measures that we hoped would capture any change in participants' emotional capacity and functioning. Four measures covered subjective wellbeing, functioning and decision-making as well as symptoms and (emergent) risks posed to self or others: the Rosenburg Self-Esteem Scale (Rosenberg, 1965), the CORE Outcome Measure (CORE System Trust, 2015; Tarescavage \& Ben-Porath, 2014); the Adult Attachment Scale (Collins \& Read, 1990); and the Making Decisions Empowerment Scale (Rogers, Chamberlin, Ellison Langer, \& Crean, 1997).

Notably, the majority of these measures do not focus primarily on a respondent's identity as an actual or potential parent. This was an important factor shaping our selection, given that neither of the evaluated services sets out either to reunite participants with the children they have lost nor to explicitly prepare them for future parenthood. Nevertheless, the participants in the services remain parents, regardless of the fact that their children have been removed from their care. Further, many of them wish to go on to have - and to keep - further children, sometimes with a new partner in a new relationship. Both factors played a part in motivating a number of women to engage with the services - regardless of their stated remits.

Given this, and after much discussion, we opted to include two further clinical measures that focused on key aspects of family functioning and potential risks that these parents might pose to future children in their care: the SCORE-15 Index of Family Functioning and Change (Stratton, Bland, Janes, \& Lask, 2010) and the Child Abuse Potential Inventory (Milner, 1986). The former focuses on the relational and systemic dimensions of family relationships. The latter assesses emergent and actual parental risk. Its limitations are much debated (see, for example, Begle, Dumas, \& Hanson, 2010). Nonetheless it offers an important perspective on risk, a question on which service managers and commissioners in child protection must focus. It also continues to be widely used in academic clinical psychological research in the field of parenting and child abuse and, therefore, used by expert witnesses working in care proceedings in English family courts. The inclusion of these two parentingoriented measures may, however, have contributed to attrition and other challenges within the evaluation.

We aimed to recruit 20 participants for this phase of the evaluation. Recruitment and retention both proved more difficult than we had anticipated. Twelve people agreed to take part in the preintervention measures but only five were willing or able to take part in the post-intervention follow-up. This requires further discussion. These birth mothers and their partners are already a highly scrutinised group. It is unsurprising that many resisted the further formal documentation of their experience through clinical assessment. Many have very negative and recent memories of psychological assessments undertaken during care proceedings. Practitioners reported that some expressed a particular reluctance to repeat some of the psychometric tests, particularly those that asked them about their 'current' parenting practices given that they no longer had responsibility for their child(ren). We felt that this unease was - understandably - likely to have contributed to the attrition rate within this element of the data collection.

Each participant in this phase of the evaluation was interviewed using the six selected measures at, or soon after, initial referral (pre-intervention) and 9-12 months later (post-intervention). The participants were interviewed in their homes or at a mutually agreed venue and were introduced to the 
interviewers by support workers. They were given the choice of filling in the self-report questionnaires on their own or having them read to them by the interviewer. At the end, all participants were asked to reflect on their experience of completing the measures.

The findings of this aspect of the evaluation should be treated with considerable caution. However, we include them here in the spirit of sharing the experiences (including the pitfalls) of developing innovative methods to evaluate innovative services to reduce recurrent care proceedings. This is relatively uncharted territory in the sense that, methodologically, it falls between a mature literature on psychologically informed parenting interventions (see, for example, van der Ende, van Busschbach, Nicholson, Korevaar, \& van Weeghel, 2014; Stratton et al., 2010, 2014) and a mature literature on psychologically informed empowerment interventions (see, for example, Rogers, Ralph, \& Salzer, 2010; Rogers et al., 1997). One clear lesson here is that, as evaluators, we needed to be more mindful of the potentially disempowering effects of methods intended to evidence empowerment. Nevertheless, the clinical measures yielded valuable data about the nature of psychological change at the personal level. Further, combining this with qualitative interview data opened up new possibilities for capturing the dynamics of empowerment from a broader evidence base.

\section{Qualitative interviews}

Practitioners in both services were acutely aware from the outset that their clients were likely to have negative feelings towards practitioners and professionals, especially those directly involved in the removal of their child(ren). As a result, both services have set out to create a qualitatively different relationship with clients, not least because they believe that fostering more positive relationships in this area of their clients' lives will benefit their relationships in others.

Given this, the evaluation team designed qualitative interviews to explore the specific quality of the relationship between clients and practitioners. In-depth interviews were conducted with 14 individuals: nine clients (eight women and one man) and five practitioners (all names have been changed to protect anonymity). They took place in a variety of locations, including the service's premises or clients' own homes, and were arranged with the assistance of practitioners. Clients were encouraged to take the opportunity to freely discuss their experiences as users of the service provided, and the factors that led to their involvement with it. Practitioners were encouraged to offer their own assessment of their work and the challenges of being involved in frontline innovation.

\section{Evaluation: key findings}

\section{Avoided pregnancies and avoided care proceedings}

Overall, we found that the two services made a significant contribution to the reduction of recurrent care proceedings in Suffolk. One of the most notable outcomes from the baseline data analysis was that none of the women clients experienced an unplanned pregnancy during the evaluation period. This is very significant given that birth mothers in this situation frequently experience 'rapid repeat pregnancy' (Broadhurst, Alrouh, et al., 2015). Our sample of 82 engaging clients included 74 women. Of these, eight were pregnant on referral and were therefore excluded from this outcome measure. One further woman was supported through a planned pregnancy. None of the remaining 65 women experienced an unplanned pregnancy. If we apply Broadhurst, Alrouh, et al. (2015) calculation that the probability of recurrence within 1-2 years of initial proceedings is $13.2 \%$, it follows that 9 (or $13.2 \%$ ) of these 65 women were likely to have become pregnant in the evaluation window and gone on to face a subsequent set of proceedings likely to end in the removal of their baby. The fact that none did was a significant outcome for both practitioners and their clients (although we recognise that the $13.2 \%$ might have included one or more of the eight women who were pregnant on referral.) The fact that one woman and her partner were, with the support of the two services, able to keep a baby born as a result of a planned pregnancy, is equally significant.

Techniques of calculating the costs of recurrence are still emergent. However, it is clear that the financial savings 'generated' from the cost of 'avoided' care proceedings are potentially substantial. Pause estimate that if 100 women with 'recurrent profiles' were resident over five sites over a fiveyear period with no intervention, they could potentially have 264 children removed at a cost of almost $£ 20$ million for care proceedings alone. Given that it would cost £9 million to run Pause for 100 women over five sites for five years, the potential cost avoidance was almost $£ 10$ million if no children 
were removed into care from the cohort (Pause, 2015b, p. 4). Our evaluation of the initial outcomes of the two Suffolk services cautiously confirms Pause's estimate of the scale of the potential savings to be made via averted costs. Using Broadhurst et al.'s recurrence rate, we calculated that 9 care cases had been avoided due to the fact that none of the 65 women in the subsample experienced an unplanned pregnancy during the 18 month evaluation window, despite having a recurrent profile. This alone could be said to have generated savings of $£ 624,000$, once offset against the costs of running the two services over that time (estimated to be $£ 186,000$ ).

It might be tempting to link these avoided pregnancies simply to the women's increased access to sexual health and contraception services. This undoubtedly played a part in shaping this crucial outcome. All participants in the two services were actively encouraged (but not required) to use some form of long acting reversible contraception (LARC) and all were encouraged to (re-)register with a GP. Visits to GP surgeries were part of a broader outcome measure - the number of referrals to other services. All M Power participants and 49 per cent of Positive Choices participants were referred on to at least one other service (with 72 and $27 \%$, respectively, being referred to between three and six services). These onward referrals, which could be regarded as a form of 'targeted reproductive health care' (Broadhurst, Shaw, et al., 2015), facilitated the uptake of LARC among many participants. However, avoided pregnancies may also have been closely linked to other aspects of their engagement with the two services, notably those which encouraged an improvement in their personal functioning and the quality of their relationships.

Baseline data drawn from practitioners' own evaluation of participants' experience of the two services suggest that $50 \%(n=80)$ were able to establish an average, good or excellent relationship with their personal support worker while $63 \%(n=70)$ forged a similarly good relationship with support workers in other agencies to which they were referred. This extended (albeit to a lesser degree) to the quality of participants' relationships with their family and friends, with $44 \%(n=73)$ described as having average, good or excellent relationships. Modest changes in levels of self-care were recorded with $35 \%(n=68)$ rated by practitioners as having average, good or excellent levels of self-care. A further significant outcome was that $23 \%$ of women clients across the two services were able to enrol in an education or training programme and $24 \%$ were able to find paid or voluntary work (noting that there is some overlap between these groups). Further evaluative research would shed much-needed light on why this aspect of the services appears to produce a greater impact for these clients than for others.

Overall, we would argue that these outcomes indicate a modest but important enhancement in clients' personal functioning and relationships and that they may have had an important bearing on the incidence of avoided pregnancies for some clients. Personal accounts offered within the qualitative interviews offer further support for this view. They shed further light on how and why these two services 'felt different' - for both clients and support workers.

\section{Experiencing a different kind of service}

For realist evaluators, 'the triggers of change in most interventions are ultimately located in the reasoning and resources of those touched by the programme' (Pawson, Greenhalgh, Harvey, \& Walshe, 2004, p. 5). They argue that because social and public policy is 'delivered through active programmes to active subjects' (ibid), methods of evaluating those policies must attend to the active subject. Since active programmes 'only work though the stakeholders' reasoning', it therefore follows that 'knowledge of that reasoning is integral to understanding its outcomes' (ibid).

The qualitative elements of our evaluation offer an insight into the reasoning of two vital groups of stakeholders within the two services: clients and practitioners. In the current policy climate, with its cautious embrace of a 'return' to 'humane social work', their views are particularly significant (Broadhurst, Hall, Wastell, White, \& Pithouse, 2010; Featherstone et al., 2014). This 'return' is, in many ways, a corollary of the rise of strengths-based approaches in child protection. 'Humane' approaches prioritise the exercise of practitioner judgement and discretion over the application of risk assessment tools alone. They also build on many earlier studies evidencing the transformative power of positive relationships (Megginson \& Cluterbuck, 2005; Scaife, 2013; Schorr, 1997). Together, this combined work creates space for the idea that practitioners are a powerful source of ground-level policy innovation. They recognise the importance of building high quality relationships between practitioners and clients. 
One of the strongest themes running across the qualitative interview data was the centrality of the relationship between clients and practitioners. All those interviewed placed enormous value on this, even participants who had entered the service with very low initial expectations. Leah describes a transition experienced by many others:

When she first knocked on my door my expectations were zero to be honest ... I was expecting absolutely nothing. I was [just] expecting to tell [another counsellor] that l'd done it and that kind of be that, something else on his list that I could tick off ... I knew I needed support and things, but I didn't think I was getting it from the ladies stood at my door, that's for sure. I was expecting nothing and what l've got back in return has been humungous, they really have proved me wrong, definitely. (Leah)

Central to the gradual building of this relationship was the fact that the practitioners were perceived as reliable, consistent and as coming without any specific agenda. Leah continued:

She doesn't have that whole professional look about her and she's not all in your face trying to tick boxes and she does that without you even realising that she's done it, and you make a step forward without you even realising and then she'll come back and say, 'Do you remember when this happened?' and you go 'Oh yeah' and just the way she is ... she's been so different to everybody else that I have ever tried to work within the past. (Leah)

Another participant, Chris, suggested that

people who can't trust are going to have a problem working with Tom, Dick, Harry every week - they are going to have a problem. But if you have got that one consistency then they'll open up a bit more and become more trusting. This consistency was closely connected with a sense of reliability: 'I could ring her and she's like, "Oh, I'm a bit busy at the minute, I will phone you back in a minute", and then 10 min later, she's rung'. (Chris).

This was echoed in practitioners' accounts of how they try to build trusting relationships with clients:

We try and do it gently in the first instance and then we just spend time getting to know each other. There is no expectation for either one of us. We encourage them not to tell us too much ... because they have been in the care proceedings things have happened to them, so they just tell you their whole life ... [So we say] 'You don't have to share every detail of your life' and try to empower them, give them control of what they say ... That's quite a big thing - to say 'It's OK, we don't need to know everything, you know, we meet you here as you are now'. (Practitioner 2)

We do build up a very warm relationship where they've never had that ... They've had a difficult time with professionals as you can imagine and they've been in and out of care and not had good, strong bonds or guidance. (Practitioner 3)

When that trust is there you can start broaching things slowly, talking about their child. For most people the loss of the children is at the forefront so that can take a lot of our first sessions, talking around the injustice - for them - of what happened. As that starts to shift slightly we can move forward. (Practitioner 1)

In addition to trust, practitioners identified four other key themes within their relationships: respect, choice, empathy and critical friendship. They also emphasised the importance of acknowledging the love that their clients had for their children and the deep shame many feel for having them removed.

Shame is something that is very little spoken about ... In society's terms you are supposed to be able to provide sufficient care for your child ... with all this stuff about what mothers are supposed to do in terms of traditional roles of motherhood. For a woman who has not been able to retain the care of child ... the societal shame that they feel is phenomenal and that does further impede them from making any steps forward. You can't just shrug that off. (Service manager 1)

Both services encourage participants to define their own personal goals. In this sense, the clients themselves play an important part in determining their own set of 'outcome measures'. Practitioners agreed that the whole process was 'very person-centred, task-centred' (Practitioner 2) and often started with 'simple, practical steps, like going for a coffee' or 'catching the bus into town'. One noted that she had had to adjust her own expectations, 'to slow right down and really celebrate the really tiny, little things' (Practitioner 1). Clients' goals could operate at a very different scale, however, and be highly instrumental. Lily wanted to deliver what she believed others wanted from her:

Yeah, as long as I have done my counselling, that's one up on me, the courts can't hold that against me, that's what social services are waiting for. l've passed everything else, it is just my counselling I need to do. (Lily) 
The inference here is that Lily believed that in continuing to engage with the service she improved her chances of either regaining contact with her existing children or her chances of keeping a future child. However, other the clients interviewed typically developed more personal programmes for change, again, often starting with modest steps:

We've set three goals. One was to identify healthy relationships because I found a lot of my friends weren't actually that great ... [Another was] learning to work with my children's social worker, because there was just something about him and l'd lose my temper with him straight away ... [and the last was] regulating my moods enough to carry on doing my support groups on a Tuesday. We've only got three for now cause if I have any more than three it overwhelms me. (Leah)

Taking and keeping ownership of these goals was also important - sometimes in the face of others' scepticism about apparently inconsequential targets.

We pick small things, to be fair, [but] my Mum was like 'They're a bit petty, aren't they? Couldn't you have picked a decent goal?' and I just looked at her and went 'But that's where you don't understand Mum because these are actually quite large goals, you have to look at it differently than the way you are,' but everybody's different, I suppose. (Leah)

Where personal goals involved accessing other services, practitioners' reliability took on a practical form in ensuring that an onward referral actually happened. Chris said that she was used to coming up against 'brick wall after brick wall' whenever she tried to get help. However, she found that her support worker could get results:

[She can] just go out there and say, 'I've got this person, needs this sort of help, can you sort something out?' And then you've got an appointment within a couple of weeks. (Chris)

Through the qualitative interviews, the participants were able to offer their own evidence of what might be described as personal empowerment in their own terms. Many reported that they felt more in control of their emotions, more able to consider others' feelings, as well as more able to articulate their own needs. For practitioners, this new level of self-awareness was linked to clients' development of more reflexive thinking:

Often they'll say to me, 'Oh God, it's starting to make sense now', they have a light bulb moment and there's a lot of tears sometimes during that period of, 'Oh God, what an idiot', 'Was that because of that?', and because I don't judge them and I help them to understand how that happened, they kind of get it and once they've got it it's, 'OK I can't really blame other people can I?'. (Practitioner 3)

Alison, a client, described her experience in terms of finding a voice:

I've learnt to speak for myself, give my opinion and not worry about what everyone else thinks. I [recently] said to my mum what my opinion was, whether she agreed on it or not, that's her problem not mine ... I used to always just be really shy about things and about saying things. But now I've learnt speak out. (Alison)

Leah recognised a change of focus:

My main motivation is me ... It used to be just the children, but (support worker) taught me over the last year that, obviously, if I'm not okay, then they're not gonna be okay anyway. (Leah).

Issy put it quite simply: 'I'm more positive. I handle things better now'.

These are modest but powerful accounts of personal empowerment, albeit offered by a small subsample of the total number of clients of the two services. Within our mixed method research design, we sought to investigate how far these accounts were borne out in our other measures. The final part of this discussion considers the evidence of empowerment within the six self-report clinical measures.

\section{Clinical measures of personal change}

The principle of taking measurement pre- and post-intervention draws on methodologies from treatment trials in health care research. In this case, we wanted to explore the possibility of measuring the services' influence on key psychological and interpersonal constructs over time. As outlined earlier, recent research suggests that women who have had children removed from their care often suffer a clear downturn in psychological functioning (After Adoption, 2007; Broadhurst \& Mason, 2013; Grant et al., 2014; Logan, 1996; Neil et al., 2010; Ryan et al., 2008). Given this, we wanted to try to capture any changes in the personal functioning of clients engaging with the two Suffolk services. 
As our own sample size was very small, we used a measure of clinically reliable change (Jacobson \& Truax, 1991) to measure individual change over time rather than a whole group comparison. A further advantage of measuring clinically significant change in relation to these kinds of services is that such measures can indicate whether, post-intervention, participants had moved from a 'dysfunctional' back into a 'functional' range thereby giving an indication as to the real-world efficacy - rather than purely statistical significance - of a given intervention.

Within our evaluation, average pre-intervention scores indicated that the majority of participants $(\mathrm{n}=$ 12) scored highly on the measure of Family Functioning (Score 20), indicating poor family functioning. On average, the Attachment scores indicated an 'anxious' attachment style, and self-esteem scores were lower than that of the non-clinical population. Baseline scores on the measure of general mental health (CORE) were overall elevated suggesting that a high proportion of this subsample would meet the threshold for a mental health diagnosis. The mean scores on the 'empowerment and optimism/feeling in control about the future' scale were low indicating low levels of empowerment at baseline. On the Child Abuse Potential measure, five participants obtained an 'elevated' score on the 'lie scale', 'abuse scale' and indicated problems in their family relationships as well as possibly indicating a risk to children. Another five participants scored in normal range on these domains.

The analysis indicated overall post-intervention improvements for the five clients who agreed to undertake follow-up self-report measures (see Table 1). One participant showed improvement on all the measures, except the empowerment scale. Three participants showed improvement on the CORE, two participants showed improvement on the self-esteem measure and two showed improvement on the decision-making scale. In summary, four of the five participants demonstrated reliable change on at least one measure and three reached clinically significant change post-intervention. No participant showed improvement on all scales.

Although these results need to be treated with caution, they do point to the positive impacts of the two services at the psychosocial level. The measures selected by the evaluation team may need further refinement but they open up an exciting new approach within mixed method evaluation, not least because they include the kinds of measures routinely used by clinical psychologists called upon to act as expert witnesses in care proceedings. The aim here was to explore ways of measuring elements of the capacity of a birth mother previously involved in proceedings to parent more effectively in the future. We explore the potential value of this new approach further through selected client case studies.

Table 1. Clinical measures case studies.

\begin{tabular}{|l|c|c|c|c|c|}
\hline \multicolumn{7}{|c|}{ Participant } \\
\hline Instrument & Alison & Tanya & Issy & Jess & Steve \\
\hline Attachment Close & $\mathrm{nc}$ & $1.09^{*}$ & $1.09^{* *}$ & $\mathrm{nc}$ & - \\
\hline Attachment Depend & $\mathrm{nc}$ & $1.36^{*}$ & $1.36^{* *}$ & $\mathrm{nc}$ & $\mathrm{nc}$ \\
\hline Attachment Anxiety & - & $0.83^{* *}$ & $0.83^{*}$ & - & $\mathrm{nc}$ \\
\hline SCORE -15 Total & $\mathrm{nc}$ & $1.04^{* *}$ & $\mathrm{nc}$ & - & $\mathrm{nc}$ \\
\hline Family Strengths & $\mathrm{nc}$ & $1.49^{*}$ & $\mathrm{nc}$ & - & $\mathrm{nc}$ \\
\hline Family Difficulties & $\mathrm{nc}$ & $1.32^{*}$ & $\mathrm{nc}$ & $\mathrm{nc}$ & $1.32^{*}$ \\
\hline Family Communication & $\mathrm{nc}$ & $1.59^{*}$ & $\mathrm{nc}$ & $\mathrm{nc}$ & $\mathrm{nc}$ \\
\hline Self-Esteem & $\mathrm{nc}$ & $3.73^{*}$ & $\mathrm{nc}$ & $\mathrm{nc}$ & $\mathrm{nc}$ \\
\hline CORE Total & $\mathrm{nc}$ & $0.61^{* *}$ & $0.61^{*}$ & $0.61^{* *}$ & $\mathrm{nc}$ \\
\hline Wellbeing & $\mathrm{nc}$ & $0.94^{* *}$ & $0.94^{* *}$ & $0.94^{* *}$ & $\mathrm{nc}$ \\
\hline Problems & $\mathrm{nc}$ & $0.86^{* *}$ & $0.86^{*}$ & $0.86^{* *}$ & $\mathrm{nc}$ \\
\hline Functioning & $\mathrm{nc}$ & $0.90^{* *}$ & $0.90^{*}$ & $0.90^{* *}$ & $\mathrm{nc}$ \\
\hline Risk & $\mathrm{nc}$ & $1.76^{* *}$ & $\mathrm{nc}$ & $\mathrm{nc}$ & $\mathrm{nc}$ \\
\hline Empowerment Total & $0.13^{* *}$ & $\mathrm{nc}$ & $\mathrm{nc}$ & $0.13^{* *}$ & $\mathrm{nc}$ \\
\hline
\end{tabular}

*indicates reliable change;

**indicates reliable and clinically significant change;

- indicates deterioration;

$\mathrm{nc}$ indicates no change made. 


\section{Mixed method case studies}

Five detailed case studies were drawn up combining personal data derived from the quantitative selfreport clinical tests and the qualitative interviews. This integrative approach offers allows for a more rounded analysis of the impact of this personalised intervention at the individual level. Synthesising the quantitative outcome data with the qualitative interview data offers a closer approximation of the participants' own experiences as service users and, importantly, offers a way of 'standardising' psychosocial measures of the effects of 'non-standard' bespoke interventions such as these. Two of the five case studies are summarised here. Both indicated clinically significant change in some elements of personal functioning and, we argue, by extension, in capacity to form more supportive personal relationships (all names have been changed). ${ }^{5}$

Alison had previously lost three children through care proceedings. She engaged with one of the Suffolk services for over 12 months, meeting face to face with her support worker every week. According to that worker, she engaged 'very well' with the service and with other professionals involved. Her engagement led to six onward referrals, including one to arrange access to contraception. Alison was also able to gain a part-time job. Alison's raw scores varied across the six self-report clinical tests. She showed a positive increase in self-esteem levels although this difference was not clinically significant. She herself commented in her interview, 'I think I am a better person, I think I have grown up more'. In regard to the other variables, clinically significant and reliable change was found for her subjective feelings of empowerment and a medium to large effect size was found for her and across all five case studies in relation to the 'power and powerlessness', 'community activism and autonomy' and 'optimism and control over the future' subscales. Alison noted, 'I've learned to speak for myself, give my opinion and not worry about what everyone else thinks'. Significantly, Alison's scores on the SCORE-15 Subscales (which explore respondents' 'strengths and adaptability', 'communication challenges' and the extent to which they feel 'overwhelmed by difficulties') were consistently low and, therefore, fell within 'normal clinical range' both prior to and after the intervention.

Like Alison, Tanya also engaged with one of the two services for one year, generally through face-toface weekly meetings. She had had one child removed from her care. Her support worker described her engagement as 'positive' and the quality of her relationships with other professionals as 'average'. Tanya took up five onward referrals, including one to assist her to access contraception. With the help of her support worker, she was able to find some voluntary work. Tanya showed reliable, positive and clinically significant change in relation to most of the self-report clinical measures. In other words, her post-intervention scores had moved closer to a level that would be expected within the non-clinical population. Tanya showed clinically significant and reliable change on every subscale of the SCORE15 and her CAP scores remained within 'normal clinical range' both pre- and post-intervention. Tanya's Attachment Anxiety score moved positively indicating that she may be moving towards feeling more securely attached within her relationships. Her CORE scores also illustrated clinically significant change on every domain, signifying that her feelings of emotional wellbeing and ability to manage her mental health have significantly improved post-intervention. In her interview, Tanya highlighted changes within her relationships with her immediate family, recalling that 'me and mum had a big falling out', that she had 'hurt [her] younger sister' and not spoken to either for several months. During her time with the service, she met them by chance: 'I was out shopping [and] they just came through the doors and then, me and mum, we cried our eyes out and hugged each other and ever since, we've seen each other nearly every day'.

Case studies like these indicate the further possibilities of gathering what might be described as the evidence of personal empowerment through a mixed methods methodology. As the use of strengthsbased approaches gathers momentum, it is increasingly important that we find ways to evaluate their impact at the individual level. If we are to capture evidence about strengths, esteem, attachment relationships and resilience, we need to ask individual clients about these areas of their psychosocial lives. Our selection of our six clinical measures - from a very broad available range - was made in an effort to do this while remaining conscious of the need to explore the emotional roots of possible ongoing risks faced (and potentially posed) by participants. 


\section{Conclusions}

'If we think that by removing child after child for the same reasons without addressing the same
problems we are doing right by the children and the families, we delude ourselves'.

(Nick Crichton, retired District Court Judge, Inner London Family Proceedings Court and member of national Pause board, 2015)

Recurrent care proceedings pose an urgent challenge to policy-makers. In the space of five years, this has moved from being a 'national problem with no name' (Cox, 2012) to an emergent policy priority attracting national debate. Pioneering research by Broadhurst et al. (Broadhurst, Harwin, Alrouh, \& Shaw, 2014; Broadhurst, Alrouh, et al., 2015, Broadhurst, Shaw, et al., 2015) has put this problem firmly on the policy map. Pioneering interventions on the ground, like those offered by the two Suffolk services reviewed here, are now playing a vital role in developing measures to help break destructive cycles. These interventions are highly personalised and draw on a growing body of strengths-based approaches within social care, child protection, health psychology and criminal justice. They aim to effect social change, in part, through the personal empowerment of marginal groups, mainly women in economically deprived communities, with unmet needs. They require careful evaluation using a mix of methods that are able to capture the experience and evidence of empowerment - where this is found - in a variety of ways.

Some have argued that the 'what works' agenda and the evidence-based policy-making of which it is a part can be a block to the development of more 'humane' forms of social work and social care (Featherstone et al., 2014). Drawing on realist and mixed methods evaluation models, this article has, by contrast, offered different kinds of evidence to suggest the two Suffolk services have been able to foster relationships that 'worked' in reducing recurrent care proceedings. Within this, it argues that the gathering, analysing and communicating of the evidence of personal empowerment - of both clients and practitioners - has a vital part to play in shaping sustainable strengths-based interventions.

\section{Notes}

1. These outcomes are administered through the following formal orders: Full Care Order, Secure Accommodation Order, Special Guardianship Order, Residence Order, Supervision Order, Family Assistance Order.

2. A full unpublished evaluation report (Cox et al., 2015) draws detailed comparisons across the two services. This article presents the evaluation findings across the two services.

3. Our combined academic and practitioner expertise cuts across child protection, domestic violence, family systems work, compassionate care, parent-infant mental health, community mental health, child and adolescent mental health, mediation, and NHS court assessment services.

4. We excluded from our analysis a further 20 clients who engaged with the services for less than two weeks.

5. For more details, see Rahemtulla (2015) Service Related Project submitted as part of the Doctoral Programme in Clinical Psychology, University of Essex. Unpublished document.

\section{Disclosure statement}

No potential conflict of interest was reported by the authors.

\section{Notes on contributors}

Pamela Cox is a professor in the Department of Sociology at the University of Essex. Her research spans social policy, social justice, social history, criminology and gender. She began working on recurrent care as a lay member of Suffolk Family Justice Council. 
Caroline Barratt is a lecturer in the School of Health and Human Sciences at the University of Essex. Her current research interests include mental health and the development of compassionate practice.

Frances Blumenfeld is a programme director and clinical lead on the doctorate in clinical psychology at the University of Essex. She has worked in child and adolescent mental health, youth offending and family therapy. She has provided expert assessments for the family courts.

Zara Rahemtulla recently completed her doctorate in clinical psychology at the University of Essex. Her 'service related project' submitted as part of this degree focused on local interventions to reduce recurrent care proceedings.

Danny Taggart is the academic director for the doctorate in clinical psychology at the University of Essex. He has worked in primary care mental health services, parental infant mental health and specialist advice services for families with young children.

Jackie Turton is a professor in Department of Sociology at Essex and is currently Deputy Dean Education for the Faculty of Social Sciences. Her research interests include maternal child abuse and child protection practice.

\section{References}

After Adoption. (2007). Moving from the sidelines: A study of the provision of independent support in Wales for birth parents and relatives of children in the adoption process. Cardiff: Author.

BBC News. (2015, December 14). Huge rise in newborn babies subject to care proceedings (report by Sanchia Berg). Retrieved from www.bbc.co.uk/news/av/uk-35090175/huge-rise-in-babiestakeninto- care

BBC Radio Four Woman's Hour. (2014, July 21). Women who've had multiple children taken into care (feature by Jane Garvey). Retrieved from http://www.bbc.co.uk/programmes/b049y3mh\#auto

Begle, A. M., Dumas, J. E., \& Hanson, R. F. (2010). Predicting child abuse potential: An empirical investigation of two theoretical frameworks. Journal of Clinical Child Adolescent Psychology., 39, 208-219.

Borzova, O. (2015). Social services in Europe: Legislation and practice of the removal of children from their families in Council of Europe member States. Strasbourg: Council of Europe.

Broadhurst, K., \& Mason, C. (2013). Maternal outcasts: Raising the profile of women who are vulnerable to successive, compulsory removals of their children - A plea for preventative action. Journal of Social Welfare and Family Law., 35, 291-304.

Broadhurst, K., Hall, C., Wastell, D., White, S., \& Pithouse, A. (2010). Risk, instrumentalism and the humane project in social work: Identifying the informal logics of risk management in children's statutory services. British Journal of Social Work, 40, 1046-1064.

Broadhurst, K., Harwin, J., Alrouh, B., \& Shaw, M. (2014). Capturing the scale and pattern of recurrent care proceedings: Initial observations from a feasibility study. Family Law. eScholarID:227563

Broadhurst, K., Alrouh, B., Yeend, E., Harwin, J., Shaw, M., Pilling, M., ... Kershaw, S. (2015). Connecting events in time to identify a hidden population: Birth mothers and their children in recurrent care proceedings in England. British Journal of Social Work, 45, 2241-2260.

Broadhurst, K., Shaw, M., Kershaw, S., Harwin, J., Alrouh, B., Mason, C., \& Pilling, M. (2015). Vulnerable birth mothers and repeat losses of infants to public care: Is targeted reproductive health care ethically defensible? Journal of Social Welfare and Family Law, 37, 84-98.

Bunn, A. (2013). Signs of Safety in England: An NSPCC commissioned report on the Signs of Safety model in child protection. London: NSPCC.

Burch, P., \& Heinrich, C. (2016). Mixed methods for policy research and program evaluation. Thousand Oaks, CA: Sage.

Cafcass. (2014). National picture of care applications in England 2013-14. Retrieved from https://www. cafcass.gov.uk/news/2014/may/national-picture-of-care-applications-in-england-for2013-14.aspx

Charlton, L., Crank, M., Kansara, K., \& Oliver, C. (1998). Still screaming: Birth parents compulsorily separated from their children. Manchester, $\mathrm{NH}$ : After Adoption.

Collins, N. L., \& Read, S. J. (1990). Adult attachment, working models, and relationship quality in dating couples. Journal of Personality and Social Psychology, 58, 644-663.

CORE System Trust. (2015). Retrieved from https://www.coresystemtrust.org.uk/ 
Cossar, J., \& Neil, E. (2010). Supporting the birth relatives of adopted children: How accessible are services? British Journal of Social Work, 40, 1368-1386.

Cox, P. (2012). Marginal mothers, reproductive autonomy and repeat losses to care. Journal of Law and Society, 39, 541-561.

Cox, P. \& Turton, J. (2016, July 8). The evidence of empowerment: Framing 'recurrent care proceedings'. Unpublished paper presented at British Society for Criminology annual conference.

Cox, P., Barratt, C., Blumenfeld, F., Rahemtulla, Z., Taggart, D., \& Turton, J. (2015). Service evaluation for Suffolk County Council and Ormiston families: Positive choices and M Power (unpublished report). Colchester: University of Essex

Crichton, N. (2015, June). Unpublished speech made at the Pause National Launch Conference.

Dale, P., Green, R., \& Fellows, R. (2005). Child protection assessment following serious injuries to infants: Fine judgements. Chichester: Wiley.

De Bortoli, L., \& Dolan, M. (2014, August). Decision making in social work with families and children: Developing decision-aids compatible with cognition. British Journal of Social Work Advance Access published, 24, 1-19.

Disley, E., Rubin, J., Scraggs, E., Burrowes, N., Culley, D. (2011). Lessons learned from the planning and early implementation of the Social Impact Bond at HMP Peterborough. MOJ Research Series 5/11. Retrieved from http://socialwelfare.bl.uk/subject-areas/services-client-groups/adult-offenders/ ministryofjustice/125755social-impact-bond-hmp-peterborough.pdf

van der Ende, P. C., van Busschbach, J. T., Nicholson, J., Korevaar, E. L., \& van Weeghel, J. (2014). Parenting and psychiatric rehabilitation: Can parents with severe mental illness benefit from a new approach? Psychiatric Rehabilitation Journal, 37, Special issue: Parents With Psychiatric Disabilities, 201-208.

Featherstone, B., White, S., \& Morris, K. (2014). Re-imagining child protection. Bristol: Policy Press.

Fetterman, D. (1994). Empowerment evaluation. 1993 Presidential Address. Evaluation Practice, 15, $1-15$.

Fetterman, D., Kaftarian, S., \& Wandersman, A. (2015). Empowerment evaluation (2nd ed.). Thousand Oaks, CA: Sage.

Gilbert, N., Parton, N., \& Skivenes, M. (2011). Child protection systems: International trends and orientations. Oxford: Oxford University Press.

Grant, T., Graham, J. C., Ernst, C. C., Peavy, K. M., \& Brown, N. N. (2014). Improving pregnancy outcomes among high-risk mothers who abuse alcohol and drugs: Factors associated with subsequent exposed births. Children and Youth Services Review, 46, 11-18.

Hill, A. (2014, October 20). Project for women with repeat children taken into care gains $£ 3 m$ boost. The Guardian. Retrieved from http://www.theguardian.com/society/2014/oct/20/projectbreakingcycle- of-children-taken-into-care-gains-3m-funding

Howe, D., Sawbridge, P., \& Hinings, D. (1992). Half a million women: Mothers who lose their children by adoption. London: Penguin.

Jacobson, N. S., \& Truax, P. (1991). Clinical significance: A statistical approach to defining meaningful change in psychotherapy research. Journal of Consulting and Clinical Psychology, 59, 12-19.

Lindley, B., \& Richards, M. (2002). Protocol on advice and advocacy for parents (Child Protection). Cambridge: Centre for Family Research, University of Cambridge. Retrieved from http://www. frg.org.uk/involving-families/parental-advocacy

Logan, J. (1996). Birth mothers and their mental health: Uncharted territory. British Journal of Social Work, 26, 609-625.

Megginson, A., \& Cluterbuck, D. (2005). Techniques of coaching and mentoring. Oxford: Elsevier Butterworth-Heinemann.

Michie, S., \& Johnston, M. (2012). Theories and techniques of behaviour change: Developing a cumulative science of behaviour change. Health Psychology Review., 6, 1-6.

Milner, J. S. (1986). The child abuse potential inventory: Manual (2nd ed.). Webster, NC: Psytec. Neil, E., Cossar, J., Lorgelly, P., \& Young, J. (2010). Helping birth families: Services, costs and outcomes. London: BAAF.

Pause. (2015a). Retrieved from www.pause.org.uk

Pause. (2015b). Pause: Creating space for change, national launch conference briefing. London: Pause.

Pawson, R., \& Tilley, N. (1994). What works in evaluation research? The British Journal of Criminology, 34, 291-306.

Pawson, R., \& Tilley, N. (1997). Realistic evaluation. London: Sage. 
Pawson, R., Greenhalgh, T., Harvey, G., Walshe, K. (2004). Realist synthesis: An introduction. ESRC Research Methods Programme, University of Manchester (RMP Methods Paper 2/2004). Retrieved from http://betterevaluation.org/sites/default/files/RMPmethods2.pdf

Rahemtulla, Z. (2015). Service related project submitted as part of the doctoral programme in clinical psychology (Unpublished document). Colchester: University of Essex.

Rogers, E. S., Chamberlin, J., Ellison Langer, M., \& Crean, T. (1997). A consumer-constructed scale to measure empowerment among users of mental health services. Psychiatric Services, 48, 1042 1047.

Rogers, E. S., Ralph, R. O., \& Salzer, M. S. (2010). Validating the empowerment scale with a multisite sample of consumers of mental health services. Psychiatric Services, 61, 933-936.

Rosenberg, M. (1965). Society and the adolescent self-image. Princeton, NJ: Princeton University Press.

Ryan, J. P., Choi, S., Hong, J. S., Hernandez, P., \& Larrison, C. R. (2008). Recovery coaches and substance exposed births: An experiment in child welfare. Child Abuse and Neglect, 32, 1072 1079.

Scaife, J. (2013). Deciding children's futures: An expert guide to assessments for safeguarding and promoting children's welfare in the family court. London: Routledge.

Schorr, L. (1997). Common purpose: Strengthening families and neighborhoods to rebuild America. New York, NY: Doubleday.

South Suffolk Pre-Birth Working Group. (2011). Action to reduce repeat pregnancies. Ipswich: Suffolk County Council.

Stratton, P., Bland, J., Janes, E., \& Lask, J. (2010). Developing an indicator of family function and a practicable outcome measure for systemic family and couple therapy: The SCORE. Journal of Family Therapy, 32, 232-258.

Stratton, P., Lask, J., Bland, J., Nowotny, E., Evans, C., Singh, R., ... Peppiatt, A. (2014). Detecting therapeutic improvement early in therapy: Validation of the SCORE-15 index of family functioning and change. Journal of Family Therapy, 36, 3-19.

Tarescavage, A. M., \& Ben-Porath, Y. S. (2014). Psychotherapeutic outcomes measures: A critical review for practitioners. Journal of Clinical Psychology., 70, 808-830.

Turnell, A., \& Edwards, S. (1999). Signs of safety: A solution and safety oriented approach to child protection. London: Norton.

Ward, H., Brown, R., \& Westlake, D. (2012). Safeguarding babies and very young children from abuse and neglect. London: Jessica Kingsley.

Wilkins, D. (2013). Balancing risk and protective factors: How do social workers and social work managers analyse referrals that may indicate children are at risk of significant harm. British Journal of Social Work, 45, 395-411.

Youth Justice Board. (2014). AssetPlus Rationale. Unpublished report by Dr. Kerry Baker report for Youth Justice Board. Retrieved from https://www.gov.uk/government/uploads/system/uploads/ attachment_data/file/367782/AssetPlus_Rationale_revised_October_2014_1_0.pdf 